\title{
Ateneo de la Juventud y Revista Amauta: dos agentes colectivos de consolidación intelectual hispanoamericana ${ }^{1}$
}

\author{
Clara María PARRA TRIANA \\ Pontificia Universidad Católica de Valparaíso, Chile/Instituto de Literatura y Ciencias del \\ Lenguaje
}

\begin{abstract}
RESUMEN
Me interesa rastrear el camino seguido por dos proyectos colectivos de la América hispana que adoptaron la reflexión humanística desde la perspectiva de le especialización en artes y letras: El Ateneo de la Juventud en México (1906-1914) y la revista Amauta en Perú (19261930), los cuales se pronunciaron y posicionaron en contra de las políticas positivistas y oligárquicas que se encontraban en auge en el pensamiento de la región y en los modelos educativos de los inicios del siglo XX principalmente. En estos dos proyectos lideraron y participaron Pedro Henríquez Ureña, Alfonso Reyes y José Carlos Mariátegui respectivamente, quienes con sus propuestas teóricas, críticas e historiográficas contribuyeron a la consolidación del campo de los estudios literarios hispanoamericanos como manifestación de nuestro pensamiento autónomo, legítimo y especializado.
\end{abstract}

Palabras Clave: Ateneo, Amauta, campo, pensamiento, crítica, estudios literarios.

Ateneo de la Juventud and Amauta magazine:

Two collective agents in Spanish American intellectual consolidation

\begin{abstract}
I am interested in searching the way followed by two collective proyects that worked around the specialization in arts and humanities in Spanish American thought: The Ateneo de la Juventud (1906-1914) in Mexico and Amauta magazine (1926-1930) in Peru. These colectivities pronounced and opposed their ideas in front of positivism and oligarchy that poured our region's thought and our education models in the early Twentieth Century. Pedro Henríquez Ureña, Alfonso Reyes y José Carlos Mariátegui leaded and participated in these projects, and by means of their theoretical and criticism proposals they helped to hold the field of Spanish American Literary Studies as an expression of our autonomous thought.
\end{abstract}

${ }^{1}$ Este artículo se enmarca en el desarrollo de mi Tesis Doctoral de la Universidad de Concepción (Chile) titulada “'La pugna secreta': consolidación del campo de los estudios literarios hispanoamericanos en los ensayos de Pedro Henríquez Ureña, Alfonso Reyes y José Carlos Mariátegui”. 
Key words: Ateneo, Amauta, field, thought, criticism, Literary Studies.

SUMARIO: 1.El Ateneo de la Juventud: educación popular, renovación intelectual y especialización del ejercicio crítico. 2.Revista Amauta: plataforma intelectual, polémica y colectiva. 3.“Arte nuevo” y "arte libre": dos formas de hacer revolución.

Los verdaderos revolucionarios no proceden nunca como si la historia empezara con ellos.

J.C. Mariátegui, "Heterodoxia de la tradición”

Entre las décadas de 1910 a 1930 encontramos en Hispanoamérica dos colectividades que fueron fundamentales para la configuración del campo de los estudios literarios: el Ateneo de la Juventud en México y la revista Amauta en Perú. En estos dos conglomerados intelectuales se propusieron y desarrollaron debates que más adelante fueron retomados, estableciendo así los discursos especializados en artes y letras que dieron paso al debate estético cultural hispanoamericano. En ellos encontramos a tres figuras intelectuales de gran relevancia para el pensamiento hispanoamericano contemporáneo: Pedro Henríquez Ureña, Alfonso Reyes y José Carlos Mariátegui, quienes conforman hoy en día la tradición de la crítica, la historiografía y la teoría literarias hispanoamericanas.

Tanto la formación de círculos de diálogo, como la edición de revistas, las conexiones editoriales, el establecimiento abierto y declarado de criterios éticos, estéticos e ideológicos, las actividades públicas y la declaración de cercanías y diferencias, son manifestaciones del empeño grupal por demarcar el terreno de especialización para la crítica y la reflexión. De esta manera cobra sentido lo que apunta Pierre Bourdieu cuando se refiere al comportamiento de cualquier campo de producción cultural, que al estar formado por grupos que "incluyen y excluyen", de acuerdo con sus intereses, estos entran en un juego de permanente lucha por definir su credo y realizar actos de progresiva innovación y apertura:

En un campo que ha alcanzado un elevado nivel de autonomía y de conciencia de sí mismo, los propios mecanismos de la competencia autorizan y fomentan la producción ordinaria de actos extraordinarios, basados en el rechazo de las satisfacciones temporales, de las gratificaciones mundanas y de los objetivos de acción corriente. (Bourdieu, 1995: 109)

Aquellos “actos extraordinarios" que indica el sociólogo francés, a veces adquieren la apariencia de actitudes heterodoxas, pues, generalmente, se oponen a un dogma o a un vacío que amenaza la productividad y la visibilidad efectiva de los productores del campo. Vamos a considerar aquí tanto al Ateneo de la Juventud 
como a la Revista Amauta a manera de agentes de producción y configuración del campo de los estudios literarios hispanoamericanos, pues sus actuaciones pusieron en marcha estrategias de existencia, congregación, visibilidad e institucionalización que provocaron que los estudios literarios hispanoamericanos ganaran un espacio simbólicamente relevante dentro de nuestra producción intelectual; de modo que lo que el lector de esta reflexión encontrará será el estudio de las formas de intervención colectiva (tanto actividades de visibilización como documentos disponibles) que los dos agentes colectivos acá estudiados nos dejaron como testimonio de su proyecto crítico.

El Ateneo de la Juventud concentró a los jóvenes que, aunque formados en la doctrina positivista predominante en las postrimerías del siglo XIX, decidieron tomar otros rumbos bajo el firme propósito de modernizar intelectualmente a México, tomando como principales ejes de controversia al sistema educativo y las actividades culturales de formación especializada en filosofía, artes y letras. Tanto los desafíos político ideológicos, como los expresamente económicos, hicieron que el Ateneo como grupo tuviera un corto periodo de existencia; sin embargo, sus actividades y proyectos trascendieron el pequeño lapso de sus labores señaladas entre 1906 y 1914.

La revista Amauta es quizás uno de los organismos editoriales más significativos de la primera mitad del siglo XX hispanoamericano. Como proyecto político social, la revista liderada por José Carlos Mariátegui removió la conciencia colectiva en una sociedad marcada por el autoritarismo, la oligarquía y las imposiciones capitalistas -en la economía marcadamente precapitalista- que perjudicaba de forma directa a los indígenas, campesinos y obreros. Como proyecto cultural, Amauta se consolida como una de las "redes editoriales" (cf. Beigel, 2006) que establece diálogos abarcadores a nivel mundial, continental y nacional, con los movimientos culturales de su contemporaneidad (superando la dedicación exclusiva a la promoción de la vanguardia, a pesar de su filiación declaradamente vanguardista).

Tanto el Ateneo como la revista Amauta se afianzan en momentos de crisis política y social, por lo que el agrupamiento y la creación de voces colectivas se presentan como una manera de afrontar los conflictos vividos en la América hispana de este periodo ${ }^{2}$.Una de las consecuencias del liberalismo económico fue la

2 La revista Repertorio Americano (1919-1958) contribuyó al encuentro de los intelectuales tanto de Amauta como del Ateneo (post-Ateneo), en los años 20. Al ser un órgano de difusión cultural de gran relevancia en todo el continente, generó y alimentó inquietudes que rebasaron los intereses eminentemente literarios, aglutinando reflexiones sobre los problemas de identidad, la raza, la producción intelectual, las amenazas imperialistas, etcétera. Esta publicación permitió que muchos intelectuales disímiles y distantes, ideológica y físicamente, conocieran el trabajo de otros y enriquecieran las propuestas realizadas en otras latitudes con sus propias experiencias. Para comprender mejor 
apertura hacia las posibilidades de profesionalización del escritor en su existencia social mediante las publicaciones periódicas. Esto reforzó no sólo la dedicación exclusiva a las letras sino también la actividad cultural de los sectores sociales que las albergaban.

\section{El Ateneo de la Juventud: educación popular, renovación intelectual y especialización del ejercicio crítico}

El Ateneo de la Juventud agrupó a algunos jóvenes que se encontraban en la capital mexicana y que compartían las inquietudes concernientes a los problemas de la educación y la reflexión filosófico-cultural. Las lecturas de estos jóvenes que en pleno gobierno de Porfirio Díaz se proponían reevaluar el papel del positivismo en la escena educativa, resultaron subversivas, sobre todo con lo que suponía una posición de marcada diferencia y crítica. El Ateneo fue para muchos de estos jóvenes, entre los que se encontraban Pedro Henríquez Ureña y Alfonso Reyes, el momento de formación y diálogo crítico que hizo las veces de escuela alterna a los estudios que cada uno de ellos adelantaba y que les permitió hacer de los estudios literarios una práctica discursiva autónoma y legítima dentro de las manifestaciones del pensamiento hispanoamericano; así lo desarrolla Víctor Barrera Enderle en su ensayo De la amistad literaria (2006):

La experiencia estética (y crítica) del modernismo es el gran antecedente del encuentro entre Alfonso Reyes y Pedro Henríquez Ureña, y lo es primordialmente porque en ella la identificación (a través de la distinción) es un factor determinante. Es una "cofradía" (un nosotros en cursiva) que requiere de la complicidad para ser efectiva. Y la amistad es una de las formas supremas de complicidad. Ese deseo de ser profesionales que había desarrollado la generación anterior, era ahora completado con una voluntad crítica. Ese sentido crítico es la primera gran distinción de la amistad entre estos dos jóvenes. La confrontación de dos interpretaciones, de dos reflexiones en ciernes. Ellos no van a conformarse con ser escritores profesionales, es decir, creadores individuales. Buscarán cubrir todo el campo literario, esto es, perseguirán una visión más amplia del fenómeno, donde se incluyan la historiografía y la crítica literarias (y lo que podríamos denominar ahora como crítica cultural). ¿Qué significa en nuestro medio la producción literaria? ¿Cuál es la función de la literatura en las sociedades latinoamericanas? Y, un cuestionamiento más peligroso, ¿qué lugar ocupa la literatura latinoamericana en la cultura occidental?, lo cual conlleva una pregunta de corte ontológico: ¿somos occidentales o sólo pretendemos serlo? (2627) [El énfasis es mío]

dicho encuentro revísese "Revista Repertorio Americano: algunos alcances de su trayectoria, 1919-1958” de Mario Oliva Medina. 
Aquellas preguntas por la función y significación de lo literario actuaron como un principio de convenio y alianza, de aquella "voluntad crítica" que los jóvenes Henríquez Ureña y Reyes se empeñaron en perfeccionar. La amistad y cercanía de los jóvenes ateneístas se presentan como instancias propicias para emprender la ganancia de autonomía del campo literario hispanoamericano, que al haber experimentado la profesionalización del escritor con el modernismo, precisó de cuestionamientos epistemológicos y de focos discursivos que se ocuparan de las letras y las artes como manifestaciones culturales. Los ateneístas no eran solo literatos, también había dentro del grupo filósofos, pintores, arquitectos, médicos, abogados y periodistas ${ }^{3}$.

Ellos tenían en común el impulso crítico sobre su entorno y se habían planteado la necesidad de buscar el rigor, la comunicación y la participación social desde la reflexión y el estudio. Quienes han reflexionado sobre las acciones del Ateneo de la Juventud lo ubican entre 1906 y 1914; la primera fecha se relaciona con la llegada de Pedro Henríquez Ureña a la vida cultural de la Ciudad de México ( $c f$. García Morales, 1992) y la segunda se señala con el auge y caída del huertismo, de gran influencia en la vida cultural mexicana (cf. Martínez, 2004) ${ }^{4}$. Dentro de este marco temporal reconocemos para efecto de nuestro análisis del campo de la producción cultural de la época, tres etapas de existencia y acción del grupo, de acuerdo con las actividades que favorecieron el desarrollo del pensamiento crítico y sus instancias de diálogo formador: a) El pre-ateneo: llegada de Henríquez Ureña a Ciudad de México en 1906, congregación del grupo en torno a Savia Moderna ${ }^{5}$, y

${ }^{3}$ Los contertulios que remarcaron más su vínculo dialógico y amistoso dentro del Ateneo son los que señala Henríquez Ureña en la carta de 1913 a Alfonso Reyes: Alfonso Cravioto, Rafael López, Roberto Arguelles, Manuel de la Parra, Ricardo Gómez Robelo, Antonio Caso y Alfonso Reyes. Este grupo fue mucho más numeroso, debido a la convocatoria que despertó la revista Savia Moderna y la tutoría de Antonio Caso, Justo Sierra y el mismo Henríquez Ureña. Con el paso del tiempo, se integraron a las discusiones ateneístas Enrique González Martínez, José Vasconcelos, Martín Luis Guzmán, Diego Rivera, Julio Torri, Carlos González Peña, Jesús Acevedo, entre otros.

${ }^{4}$ Manuel Olguín (1956) establece sólo dos etapas al estudiar la primera parte de la formación de Alfonso Reyes como pensador. Denomina a los compañeros de Reyes como "la Generación del Centenario", y ubica el primer periodo entre 1906 y 1910 (preateneo/Ateneo), y el segundo entre 1911 y 1914 (Ateneo/Universidad Popular). José Luis Martínez (2004 [1986]) en el prólogo a la Correspondencia A. R./P.H.U divide en tres los momentos identificables de este periodo, de acuerdo con la agitación política: 1907-1910 (fin del Porfiriato/celebración del Centenario y revolución maderista), 1910-1913 (presidencia de Madero y asesinato de este), y por último, principios de 1913-finales de 1914 (régimen huertista -derrota y caída- y estallido de la Primera Guerra Mundial).

${ }^{5}$ Savia Moderna fue una revista cultural de corta y poca difusión. Su importancia radica en la función de plataforma intelectual que cumplió en el periodo en el que los pre-ateneístas iniciaron su reconocimiento como actores culturales. 
establecimiento de la Sociedad de Conferencias en 1907; b) La fundación propiamente dicha del Ateneo de la Juventud en 1909 y continuación de las conferencias por ciclos temáticos, y c) La acción institucional del Ateneo: creación de la Escuela de Altos Estudios en 1910, fundación de la Universidad Popular en 1912, y creación de la primera Facultad de Humanidades.

Conscientes del papel de gran relevancia que tuvo este período de la historia cultural mexicana, tanto para el espacio intelectual hispanoamericano como para su propia formación, Henríquez Ureña y Reyes escribieron algunos textos en los que plasmaron sus visiones de conjunto, tales como: "Conferencias" [1908], "La cultura de las humanidades" [1914], "La influencia de la Revolución en la vida intelectual de México" [1924] del dominicano; "Nosotros” [1914], "Pasado inmediato” [1939] y "El testimonio de Juan Peña” [1930] de Reyes 6 .

La posición crítica ante la vida cultural y política que asumieron los ateneístas se destacó porque respondieron críticamente al positivismo en lo concerniente a su influencia en la instrucción pública; por otra parte, reaccionaron en contra del esteticismo de las tendencias literarias y artísticas del momento que desde su punto de vista reiteraban propuestas estéticas ya exploradas y reconocidas. Las artes que criticaron apostaban por elaboraciones verbalistas atadas a una vieja concepción del arte original, la cual no superaba la significación del modernismo, pero sí acrecentaba su decadencia.

En el sentido político, su evaluación del positivismo denunció el tipo de organización que experimentaba el país, en detrimento de las clases populares en las que el hambre y el analfabetismo eran comunes, mientras que las clases acomodadas gozaban de los beneficios de una plutocracia que les favorecía, procurándoles comodidades y políticas de inmovilidad de clases. En el plano educacional observaron que la propuesta laicista de Gabino Barreda había sido llevada al plano del materialismo y el tecnicismo, eliminando casi sin apelación alguna, la educación en letras, artes y filosofía, tal como lo podemos leer en "La influencia de la Revolución en la vida intelectual de México” [1924]:

En aquel período [1906-1911], bajo el gobierno de Díaz, la vida intelectual de México había vuelto a adquirir la rigidez medieval, si bien las ideas eran del siglo XIX, "muy siglo XIX". Toda Weltanschauung estaba predeterminada, no ya por la teología de Santo Tomás o de Duns Escoto, sino por el sistema de las ciencias modernas interpretado por Comte, Mill y Spencer; el positivismo había reemplazado al escolasticismo en las escuelas oficiales, y la verdad no existía

${ }^{6}$ Dentro de las cartas que se escribieron Pedro Henríquez Ureña y Alfonso Reyes, la escrita el 29 de octubre de 1913 en México, exhibe los nombres y actividades que llevó a cabo el grupo junto con algunas distancias personales e intelectuales que profesa Henríquez Ureña. La carta fue la base de un texto que Reyes tituló "Nosotros" y que con mayor elaboración se publicó posteriormente con el título de "Pasado inmediato". 
fuera de él. [...] el único camino era imitar a Europa. ¡Y qué Europa: la de los deplorables salones oficiales! En música, donde faltaba una tradición nacional fuera del canto popular, se creía que la salvación estaba en Leipzig. (Henríquez Ureña, 2001: 611-612)

Henríquez Ureña, a nombre de sus compañeros ateneístas manifiesta la necesidad de la educación popular de calidad, que se diferenciara de la educación de élite que recordaba a la Edad Media en sus métodos, estructura y objetivos. La actitud de debate adoptada por la nueva generación buscó en la universidad el terreno propicio para llevar a cabo sus proyectos culturales. Esta sería un espacio alejado de influencias políticas oficialistas, poseedor del más hondo sentido ético en torno al conocimiento moderno, el diálogo y la participación social, de allí los esfuerzos del Ateneo por constituir la Universidad Popular Mexicana en 1911.

A nivel estético los jóvenes se organizaron en defensa de lo que denominaron "Arte Libre", en la "Protesta literaria" 1907, la cual se convierte en el manifiesto del grupo de intelectuales que no estaba dispuesto a tranzar con las posturas estéticas carentes de profundidad y que, por el contrario, asumía con integridad la lucha simbólica que significaba demostrar oposición y confrontación pública. Para comprender mejor su postura, cito partes claves de la protesta:

\begin{abstract}
...aquí es oportuno declarar a manera de credo, que nosotros no defendemos el modernismo como escuela, puesto que a estas horas ya ha pasado, dejando todo lo bueno que debía dejar y ya ocupa el lugar que le corresponde en la historia de la literatura contemporánea; lo defendemos como principio de libertad, de universalidad, de eclecticismo, de odio a la vulgaridad y a la rutina. Somos modernistas, sí, pero en la amplia acepción de ese vocablo, esto es, constantes evolucionadores, enemigos del estancamiento, amantes de todo lo bello, viejo o nuevo, y en una palabra, hijos de nuestra época y de nuestro siglo. (Cit. en García Morales, 1992: 54)
\end{abstract}

Este credo del "Arte Libre” defiende la formación de una mirada amplia, que supere los verbalismos y la pereza intelectual; para los firmantes del manifiesto ser "verdaderamente cultos" (Id.) significa tanto poseer una gran erudición, como tener la capacidad de hacer algo con la ella, es decir, ejercer crítica lúcida, dinámica y moderna para influir en el despertar de conciencia de la sociedad contemporánea.

${ }^{7}$ La "Protesta literaria" es un documento que firman todos los contertulios de Savia Moderna, en abril de 1907. En ella se declara la renovación intelectual que pretendían los jóvenes, ya no sólo en el plano de la creación sino también en el del estudio y la crítica. La particularidad de este documento es su creencia manifiesta en el estudio, el rigor y la pluralidad del pensamiento. Se puede leer la conferencia completa en el libro de Alfonso García Morales, citado anteriormente. 
Con "La Sociedad de Conferencias"8 el grupo comienza a aparecer públicamente, ya no sólo como una manifestación airada de deseo de cambio, sino más importante aún, con propuestas académicas concentradas y desarrolladas de manera metódica. En estas actividades los ateneístas presentaron largas jornadas de diálogo literario y filosófico en torno a temas clásicos y modernos. Las conferencias se mostraron como la ocasión propicia para abrir las discusiones al público, enriquecer la vida cultural capitalina y hacer un llamado a la especialización. Los conferencistas evitaron al máximo el didactismo de la cátedra y el tono laudatorio de los homenajes; ellos se presentaron como verdaderos expertos conscientes de estar configurando un público ajeno a gustos oficialistas e impresionistas, que se orientara más hacia la interlocución con el pensamiento occidental. Así lo expone el dominicano en Horas de estudio de 1910:

La principal facultad por ellos [los conferencistas] revelada es, a mi ver, espíritu filosófico. Filosófico, si se quiere, en significación más extensa de lo que es usual: espíritu capaz de abarcar con visión personal e intensa los conceptos del mundo y de la vida y de la sociedad, y de analizar con fina percepción de detalles los curiosos paralelismos de la evolución histórica, y las variadas evoluciones que en el arte determina el inasible elemento individual. (Henríquez Ureña, 2001: 171) [El énfasis es mío]

Desde la perspectiva de Henríquez Ureña, el valor agregado de las conferencias presentadas por los jóvenes mexicanos fue el de la fusión perfecta entre la "facultad artística” y el "espíritu filosófico", cuyas fortalezas traducían una "potencialidad creadora, de imaginación y sensibilidad”, es decir, "capacidad crítica” para descubrir en el arte visiones del mundo, de la vida y de la sociedad.

La "potencialidad creadora, de imaginación y sensibilidad" que caracterizaba, según el dominicano, a aquella "facultad filosófica", era la manifestación del pensamiento moderno: apertura, receptividad, inconformidad y sentido crítico. Las conferencias presentadas por ciclos trataban asuntos de diverso interés, pero siempre con un sentido de contemporaneidad, tales como filosofía moderna,

${ }^{8}$ Los ciclos de conferencias a los que nos referimos se llevaron a cabo entre 1907 y 1909. Diferentes ciclos, variadas temáticas, rotación de los conferencistas y diversidad de actividades en torno a éstas fueron sus características más relevantes. No podemos dejar de recordar las palabras de Víctor Barrera Enderle al respecto: "La conferencia presenta una legitimación que no temo en llamar 'académica'. Su alcance pretende ser mayor ('al público en general') y precisa de un sujeto experto en el tema por tratar. La conferencia requiere de estudio y perfeccionamiento. No es un simple y apasionado caso de recitación (más cercano a los reinos de la inspiración), sino un acercamiento especializado al asunto y tema dados” (Barrera Enderle, 2006: 47). 
música, artes plásticas, crítica literaria, arquitectura, literaturas en otras lenguas, entre otros.

De los testimonios dejados por los ateneístas para el futuro de las letras hispanoamericanas, resalta la exactitud y conciencia de Alfonso Reyes en su texto "Pasado inmediato". Allí Reyes se propone, aparentemente, buscar el germen de la idea de la Revolución Mexicana, pero lo que en realidad muestra es una visión crítica de lo que pasaba con la inteligencia, la educación y la cultura en el período en que se desarrollaba la Revolución. Queda claro con el testimonio de Reyes, que los ateneístas no estaban ligados políticamente a la Revolución, aunque sí la acompañaron en sus preocupaciones "educativas y sociales"9. Reyes rechazó la dedicación vital a la política, apreciándola con distancia crítica. Su cuestionamiento al sistema educativo de la Escuela Nacional Preparatoria del gobierno de Porfirio Díaz apunta a la pobreza de la formación impartida por su "asepsia metafísica y cultural”. Reyes reclama para la formación académica la necesidad de adquirir conciencia de la historia mediante la formación humanista.

Un síntoma sólo en apariencia pequeño, de aquella descomposición de la cultura: se puso de moda, precisamente entre la clase media para quien aquel sistema escolar fue concebido, el considerar que había un cisma entre lo teórico y lo práctico. La teoría era la mentira, la falsedad, y pertenecía a la era metafísica, si es que no a la teológica. La práctica era la realidad, la verdadera verdad. Expresión, todo ello, de una reacción contra la cultura, de un amor a la más baja ignorancia, aquella que se ignora a sí misma y en sí misma se acaricia y complace. Cuando una sociedad pierde su confianza en la cultura, retrocede hacia la barbarie con la velocidad de la luz. (Reyes, 1997: 193 [El énfasis es mío])

La cultura vio una vez más amenazado su espacio propio y los ateneístas se propusieron edificarlo y custodiarlo. Encontraron en la Escuela Nacional de Jurisprudencia el lugar seguro para dedicarse a la lectura y a la escritura. Una vez consolidado el grupo del Ateneo en 1909 en la Escuela de Derecho, y después de haber ganado un público constante con las sesiones de conferencias, Justo Sierra funda la Escuela de Altos Estudios que pronto se vincula a la Universidad Nacional Popular, la cual ofrecía talleres gratuitos a personas que no podían pagar su educación superior; este ideal de instrucción pública y popular se extendió por toda Hispanoamérica.

9 La orientación política de los ateneístas no fue homogénea. Dentro de las personalidades más moderadas sobresalen Henríquez Ureña y Reyes. Los demás se debatían entre la oposición irreconciliable al gobierno de Díaz, por un lado, y la adhesión al huertismo, por otro. 
Fue así como los ateneístas, tocados por un gran sentido de responsabilidad social e histórica en relación con la lucha por la ganancia de un espacio propio para reflexionar sobre las naciones y sus producciones culturales, se distanciaron radicalmente de la torre de marfil modernista, con el fin de trabajar por la reforma educacional que procuraba la concientización colectiva del cultivo del pensamiento. A pesar de que existían diferencias políticas e ideológicas al interior del grupo, los proyectos de extensión y especialización fueron defendidos desde el estudio sistemático de la identidad nacional, está concebida en sentido amplio, pues ya no se pensaba sólo en México, ahora había que pensar en la Hispanoamérica que se abocaba al reconocimiento de sus facultades y necesidades.

\section{Revista Amauta: plataforma intelectual, polémica y colectiva}

La revista Amauta es el proyecto editorial que muestra la madurez y trayectoria de José Carlos Mariátegui, en una carrera que buscó definir una voz de conciencia intelectual para Hispanoamérica; así lo afirma Nelson Osorio (1988) en su estudio titulado "Mariátegui y Amauta en el contexto de los años veinte", en donde se estudia la capacidad aglutinadora del proyecto intelectual-editorialista mariateguiano. Osorio reconoce a Amauta como un órgano que, comparado con otros de la época, supo crear una red de comunicación, reflexión y reconocimiento de los problemas del Perú y en extensión de Hispanoamérica como ninguna otra revista vanguardista de su momento. Pocos fueron los proyectos editorialistas que alcanzaron tal resonancia a nivel continental y mundial, pues, ya fuera por las condiciones económicas, por las convicciones estético-ideológicas de sus promotores o por las carencias en asuntos de compromiso y constancia, las revistas se cerraban en sí mismas por la limitación de sus propuestas, provocando su desaparición.

Dado su carácter aglutinador, es decir, su capacidad de convocar a las más diversas percepciones de las realidades problemáticas desde las perspectivas del debate y la confrontación, Amauta tuvo la posibilidad de convertirse en la plataforma intelectual hispanoamericana más importante de los años veinte. Mariátegui, el amauta, como lo llamaban sus compañeros de proyectos, funda la revista después de un periplo editorialista que Fernanda Beigel (2006) denomina “editorialismo programático mariateguiano", integrado por todos los proyectos de publicación adelantados por el pensador peruano desde 1918 hasta su muerte en 1930:

Las revistas latinoamericanas de vanguardia durante los años veinte eran la expresión predominante de proyectos colectivos. A diferencia de las creaciones literarias o escuelas artísticas en las que se manifestaba una sensibilidad particular, las revistas eran vehículo de grupos que otorgaban un carácter performativo a las inquietudes sociales y culturales que emanaban de esa sensibilidad. Las revistas de mayor trascendencia se caracterizaron por el intento 
de aglutinar distintas manifestaciones de la llamada "nueva sensibilidad", y estaban atravesadas por una constante que hacía las veces de "cable a tierra” con la sociedad que rodeaba a estos nuevos escritores y artistas: la preocupación por lo social. (Beigel, 2006: 64)

Como ya sabemos, Mariátegui ingresa al campo cultural peruano mediante su actividad en la prensa, y, poco a poco, va desarrollando inquietudes por la independencia en la comunicación de las ideas y la formación de criterio ideológico, social y cultural. Ser periodista no le bastaba, necesitaba comenzar a generar espacios legítimos de reflexión. Es por ello que toma distancia del diarismo publicitario y oficialista (únicas formas seguras de ubicación dentro del campo periodístico de la época) y se inicia en el editorialismo vanguardista más cercano al periodismo de reflexión y opinión.

La incursión de Mariátegui en la escena editorial peruana se distingue por su empeño en el cultivo del desarrollo de las ideas, más que en la transmisión exclusiva de información. En las propuestas mariateguianas existe una conjunción entre el periodismo informativo, que supera las coyunturas y las modas, y el periodismo de opinión, este último clave en lo que tanto defenderá en su posicionamiento que tendrá como objetivo central "la interpretación de la realidad”. Con el diario Nuestra época fundado en 1918, Mariátegui articula el periodismo de opinión como una forma de oposición ante el aburguesamiento y esteticismo, tanto de los diarios triviales de circulación popular, como de las revistas de doctrina literaria que buscaban solo lectores simpatizantes.

La edición de revistas y periódicos se ofrece a Mariátegui como la mejor alternativa para crear conciencia y ejercer influencia en la realidad desde el punto de vista intelectual e ideológico. La revista hacía las veces de tribuna desde la cual era posible pronunciarse, argumentar una posición e intervenir en el presente. Era una forma de participar activamente en la historia -como tanto lo deseaba el pensador peruano-, y dejar en evidencia que la inteligencia peruana e hispanoamericana estaba llevando a cabo proyectos propios para comprender el panorama del mundo. Con un fuerte e irrebatible interés por su presente (y por el futuro hispanoamericano), las revistas mantuvieron los ojos puestos en las problemáticas de posguerra, la Revolución Rusa, la Revolución Mexicana, la Reforma Universitaria, las vanguardias estéticas y políticas, entre otras, siendo estas últimas los aspectos de mayor capacidad abarcadora, pues los debates que protagonizaron articulaban el arte y la política como dos manifestaciones de acción histórica.

Mariátegui se propuso remover la actividad editorial y periodística en el Perú, apostándole a una red que generara lazos intelectuales de comunicación tanto internacional como de la capital peruana con las provincias. Su objetivo principal era explorar la realidad y debatirla desde todos sus frentes; fue así como con las revistas que fundó y/o dirigió, tales como Nuestra época (1918), La razón (1919), 
Claridad (1923), realizó un trayecto que alcanzó la madurez con Amauta (19261930), cuya publicación ostentaba claras tendencias y tomas de partido.

Es propicio recordar que durante las jornadas de definición de Amauta como proyecto editorial, Mariátegui publica La escena contemporánea (1925) y Siete ensayos de interpretación de la realidad peruana (1928). Los dos libros de apariencia miscelánea exploran, por un lado, las problemáticas mundiales desde sus implicaciones para el presente y para la historia, y, por el otro, la toma de conciencia para promover cambios en los que el Perú entrara a participar activamente en el escenario mundial. Evidentemente, los dos textos son coherentes con los objetivos trazados por el editorialismo de Mariátegui. El primero sale a la luz a la vuelta de Europa del autor, es decir, cuando entra en su etapa autodenominada "de madurez"; mientras que el segundo se convierte en el libro que engloba y condensa mejor su posición intelectual, política e ideológica, ante los problemas del Perú y de la América Indo-íbera. Cabe señalar que su "edad madura” coincide justamente con el período de gobierno de Augusto Leguía (1919-1930), frente a quien se manifiesta la posición antioligárquica que Mariátegui y sus compañeros de generación presentan en sus escritos ${ }^{10}$.

Amauta, en este sentido, es el producto de Mariátegui como "intelectual orgánico”, según el ejemplo y las palabras de Antonio Gramsci en Cuadernos de la cárcel,

... ser [un] nuevo intelectual ya no puede consistir en la elocuencia motora, exterior u momentánea de los afectos y de las pasiones, sino que el intelectual aparece insertado activamente en la vida práctica, como constructor, organizador, “persuasivo permanente”, no como simple orador -y sin embargo superior al espíritu abstracto, a partir de la técnica-trabajo llega a la técnica-ciencia y a la concepción humanista histórica, sin la cual se es "especialista” y no se llega a ser “dirigente” (especialista+político). (15)

10 Muchos de los críticos de la obra del amauta han tomado como referencia la periodización que el propio Mariátegui pronunció sobre sus escritos. Él denominó como su “edad de piedra” a los primeros escritos publicados en La prensa, El Turf o Lulú (estas publicaciones tenían carácter comercial y burgués), sus escritos poéticos en Colónida, y sus publicaciones de carácter militante en Nuestra época y La razón (cf. Flores Galindo, en Mariátegui, 2005), o sea, sus textos de 1911 a 1918. Su "edad madura”, que inaugura con el rechazo a su pseudónimo "Juan Croniqueur”, continua con sus escritos producidos desde Europa desde 1919 y concluye con su muerte en 1930. En este último período se encuentra la publicación de artículos y estudios estéticos en las revistas Mundial y Variedades, además de la fundación y dirección de Claridad, Amauta y Labor. De algunos de los artículos publicados en estos periódicos y revistas se constituyen sus dos obras publicadas en vida. El estudio introductorio a los textos esenciales de Mariátegui, realizado por Alberto Flores Galindo y Ricardo Portocarrero Grados, nos explica ampliamente esta periodización básica. 
Para el pensador italiano, y para el amauta, los intelectuales tienen a su cargo dar conciencia a su clase, por medio de la búsqueda de autonomía y coherencia en la formulación y transmisión de las ideas, tratando de ser al mismo tiempo tanto especialistas como dirigentes y técnicos, mediante el manejo en su área y las aledañas.

En cuanto proyecto cultural, la revista Amauta se configura como el espacio simbólico en el cual se agrupan los intelectuales peruanos, hispanoamericanos y los pertenecientes a la red de apoyo que establece Mariátegui a distancia, bajo una denominación no necesariamente cronológica, pero que sí marca una actitud ante el ejercicio crítico: la así llamada "nueva generación" que ostenta un "nuevo espíritu". Esta creencia en la nueva generación, que se traducía más en la fe en una actitud que revolucionara lo establecido y lo consabido, comparte con el credo del Ateneo de la Juventud, el deseo por traer a la escena cultural contemporánea nuevas voces y perspectivas que debatieran desde puntos de vista menos afirmativos y más críticos $^{11}$.

No sin razón postula Adalbert Dessau (1971) en su ya clásico estudio sobre la relación entre literatura y sociedad en la obra de José Carlos Mariátegui que la verdadera presencia del marxismo en la postura crítica del peruano se orientó al despertar de conciencia de clase. Los intelectuales que participaron en el proyecto cultural que encarnaba la revista Amauta, de una u otra forma coincidían con la idea de que la revolución tenía sus bases en la creación, y esta se encontraba por excelencia en las expresiones más libres que había podido alcanzar la humanidad, es decir, en el arte y la literatura; en este sentido actuaba como el gran motor renovador y revolucionario para tal despertar de conciencia (conjunción entre materialismo marxista y espiritualismo bergsoniano, $c f$. Dessau)

La conciencia a la que apelaron los intelectuales integrados al proyecto de Amauta fue aquella que tuviera la capacidad de tomar partido, mediante la aceptación de una postura particular y frontal. Es así como en la "Presentación de Amauta" señala enfáticamente Mariátegui: "Amauta no es una tribuna libre. [...] no concebimos una cultura y un arte agnósticos” (Mariátegui, 2005: 358). Para Mariátegui la libertad tiene más que ver con la posibilidad de declarar abierta y públicamente una "filiación y una fe", que con la concepción de deambular sin

11 María Helena Goicoechea señala en su artículo "Amauta: proyecto cultural de Mariátegui” (1993) que la revista surge como testimonio del proceso de modernización del Perú, haciendo evidentes las rupturas y desarticulaciones que sufría el país en su proceso de adaptación a nuevos órdenes y despertar de conciencia de sus intelectuales. Reconoce la estudiosa como categorías centrales en el contenido de Amauta la culturalista, la nacionalista, la socialista, la indigenista y la académica; y resalta a la académica con debates sobre el "arte nuevo" y el indio como los temas de mayor preponderancia. 
sentido y sin convicciones en una realidad que necesitaba de líderes y voces consecuentes y críticas.

Al proclamarse Amauta como un organismo de vanguardia, además de ligarse estética e ideológicamente con esta tendencia, se manifiesta un lugar de enunciación diferencial, especializado y exigente ante las nuevas creaciones del espíritu. En “Aniversario y balance”, texto editorial de la revista publicado en 1928, Mariátegui reitera la adhesión a una idea de la historia creadora, madura, que le permita a América reflexionar sobre su realidad con los pies en la tierra:

La primera obligación que toda obra, del género de Amauta se ha impuesto, es esta: durar. La historia es duración. No vale el grito aislado, por muy largo que sea su eco; vale la prédica constante, continua y persistente. No vale la idea perfecta, absoluta, abstracta, indiferente a los hechos, a la realidad cambiante y móvil; vale la idea germinal, concreta, dialéctica, operante, rica en potencia y capaz de movimiento. Amauta no es una diversión ni un juego de intelectuales puros: profesa una idea histórica, confiesa una idea activa y multitudinaria, obedece a un movimiento social contemporáneo. (Mariátegui, 2005: 450)

La postura intelectual de Mariátegui y en extensión de Amauta fue la de generar discusiones de largo aliento, coherentes con la pluralidad de realidades indo-íbero americanas, en las que las relaciones entre arte, literatura y política fueran un eje creador y crítico, no reivindicativo. De allí se deriva la postura evaluativa ante el populismo literario que encarna una literatura ostentadora de una "cuantiosa clientela” pequeño burguesa, acomodada a las tendencias demagógicas carentes de evaluación de los procesos históricos y la construcción de criterios propios.

Cuando Mariátegui se refiere a una "verdadera experiencia" en el caso del suprarrealismo, engloba a su vez una discusión que determinará el aporte de esta nueva generación crítica: la de hacer de la interpretación, la historización y el estudio del arte literario una experiencia del sujeto, es decir, la subjetivización del acercamiento al objeto estético, en evidente oposición al establecimiento de una "objetividad" metamorfoseada del discurso científico que pretendía, desde una perspectiva positivismo, defender la objetividad y la no intervención del sujeto en los procesos cognoscitivos e interpretativos.

\section{“Arte nuevo" y “arte libre”: dos formas de hacer revolución}

No puedo dejar de atender a estos dos llamados que realizaron los colectivos de la revista Amauta y el Ateneo de la Juventud respectivamente. En su íntimo y declarado deseo de revolucionar los órdenes establecidos, los jóvenes de estas dos agrupaciones lanzan propuestas no solo a nivel político-educativo sino también al anquilosamiento de las posturas estéticas que se autodenominaban nuevas. En sus críticas "la decadencia” o el "decadentismo" figura como la postura que hay que combatir, para edificar sobre ella artes más genuinos y dialogantes con su 
contemporaneidad y no aquellos que se limitan a la rememoración nostálgica de pasado estético exitoso.

Encontramos la exigencia del "arte libre" en la "Protesta literaria" de los jóvenes ateneístas que cité en páginas anteriores. En ella se percibe una apuesta por la renovación y, de manera concomitante, el llamado al conocimiento reflexivo de las expresiones artísticas. La idea de arte libre no alude directa y expresamente al arte vanguardista, este tiene más que ver con una posición ética -no técnica ni de ejecución-, un ethos de independencia intelectual y de libertad para el encuentro con una experiencia estética sin limitaciones. El arte libre es una forma de militar desde la experiencia auténtica, de hacer propio e indelegable el encuentro con las visiones de mundo que entrega el arte, de acceder al la forma de conocimiento que al que todos tienen derecho y que pocos reconocen como un espacio común: "Pisamos un terreno que no es exclusivo patrimonio de nadie; un campo que es del que lo tome por asalto, sin pedir permiso a nadie: del que lucha y se bata mejor y con más fuerzas: del que golpea más duro" ("Protesta literaria”, citada en García Morales).

Con un coincidente llamado ético Mariátegui expone en "Arte, revolución y decadencia” [1926], artículo publicado en Amauta, que un "arte nuevo" es aquel que renueva el espíritu y no sólo se concentra en la técnica y la forma. Mariátegui se refiere a las manifestaciones vanguardistas, a las cuales les exige ser verdaderamente revolucionarias, con la genuina adopción de un soporte espiritual referido a una toma de posición política. La decadencia o el arte decadente sería aquel que insiste en el escepticismo nihilista del agnosticismo enmascarado tras la técnica. Las vanguardias en su proceso de creación, crecimiento y crítica soportan la pugna, "el agón”, entre la decadencia y la revolución. El problema que plantea Mariátegui en relación con el arte nuevo es muy complejo. Él conjuga problemáticamente las relaciones estructurales entre política (entendida como una religión), economía y manifestaciones estéticas, en un ir y venir de dependencias recíprocas. Para el amauta "arte nuevo" es igual a revolución en las ideas, renovación de los órdenes y capacidad de respuesta ante los problemas contemporáneos. Solo así entiende Mariátegui al arte que es capaz de acusar una crisis. El arte-purismo, ya emparentado con el "arte nuevo" de la proclama vanguardista, posee la carga espiritual que Mariátegui le exigía al arte: una promesa de futuro. Porque no solo se trataba de renovar la técnica, sino ante todo que los artistas lograran mostrar que queda siempre mucho por hacer y por decir, que todo intento artístico es construcción, no demolición.

De modo que el "arte libre" ateneísta y el "arte nuevo" del vanguardismo proclamado por Amauta se encuentran en un momento histórico en el que las ideas estético-literarias en Hispanoamérica se encuentran en la ebullición de un nuevo orden. En este preciso momento (años '20) la lectura literaria pide su propio espacio de definición especializada y como tal busca liberar la idea de lo estético de lo meramente ornamental o de lo ancilar en tanto servicio a otras esferas de acción humana como lo era la política. El arte debía ser militancia, sí, por supuesto, pero 
esa militancia debía darse en el orden adecuado a su objeto y no a la inversa. Militar desde el arte y las humanidades implicaba ser verdaderos humanistas, con un pleno sentido de la carga de futuro que contienen las expresiones de carácter estético; así lo entendieron los ateneístas y así lo concibieron los colaboradores de Amauta.

Hasta aquí hemos visto de qué manera las actividades de dos proyectos colectivos, del Ateneo de la Juventud y de la revista Amauta, han colaborado en la solidificación y apertura de los estudios literarios en Hispanoamérica, como discursos que desde su génesis tomaron para sí la labor de trazar modos de acercamiento a las problemáticas socio-culturales, mediante la consolidación de líneas de pensamiento. Estos impulsos juveniles pronto se convierten en convocatoria abierta para el ejercicio de una actividad crítica que tiende a ensancharse. Desde sus inicios y con los efectos de la trayectoria llevada a cabo por nuestros pensadores, los estudios sobre la literatura no se presentan "deslindables" de los conflictos que los rodean, incluso, se hace legible desde su postura que la literatura participa activamente en las dinámicas sociales no como reflejo irrefutable sino como evaluación crítica. Si bien para nuestros pensadores y sus compañeros de generación les era necesario plantearse intelectualmente desde un frente definido, no negaron que los problemas de la cultura pasaban sin discusión por los terrenos de la política, la economía y el bienestar de los pueblos. Un pueblo sin educación de calidad, por ejemplo, sería incapaz de sacar adelante la idea de pensar por sí mismo, de ahí sus inquietudes por la Reforma Universitaria y la consecuente Educación Popular defendida por los jóvenes ateneístas y los promotores de Amauta. La apuesta juvenilista, que pronto madura en concepciones de creación, existencia social y proyectos de largo aliento, le dio a los estudios literarios hispanoamericanos, desde sus inicios en la búsqueda de institucionalización, el deseo de controvertir con el presente, ampliar el espectro del lectura y adoptar la interpretación crítica como método para cuestionar desde el arte a la realidad circundante.

\section{BIBLIOGRAFÍA}

BARRERA ENDERLE, Víctor.

2006 De la amistad literaria (ensayo sobre la genealogía de una amistad: Alfonso Reyes/Pedro Henríquez Ureña, 1906-1914). Monterrey: Ediciones del festival Alfonsino/Universidad Autónoma de Nuevo León.

BEIGEL, Fernanda.

2003 El itinerario y la brújula: el vanguardismo estético-político de José Carlos Mariátegui. Buenos Aires: Biblos. 
2006 La epopeya de una generación y una revista. Las redes editoriales de José Carlos Mariátegui. Buenos Aires: Editorial Biblos.

BOURDIEU, Pierre.

1995 Las reglas del arte. Estructura y génesis del campo literario. Barcelona: Anagrama.

DESSAU, Adalbert.

1971 “Literatura y sociedad en las obras de José Carlos Mariátegui”, en Mariátegui, tres estudios. Lima: Empresa Editora Amauta.

GARCÍA MORALES, Alfonso.

1992 El Ateneo de México 1906-1914. Orígenes de la cultura mexicana contemporánea. Sevilla: Escuela de estudios hispanoamericanos de Sevilla.

GOICOECHEA, María Helena.

1993 "Amauta: proyecto cultural de Mariátegui”. Anuario Mariateguiano, $\mathrm{n}^{\circ}$ 5, vol. V (1993): 27-38.

GRAMSCI, Antonio.

1975 Cuadernos de la cárcel: los intelectuales y la organización de la cultura. Ciudad de México: Juan Pablos Editor.

HENRÍQUEZ UREÑA, Pedro.

2001 Obra Crítica [1960]. Ciudad de México: F. C. E.

HERNÁNDEZ LUNA, Juan (comp.).

1962 Conferencias del Ateneo de la Juventud. Ciudad de México: UNAM.

MARIÁTEGUI, José Carlos.

2005 Invitación a la vida heroica. José Carlos Mariátegui. Textos esenciales. Alberto Flores Galindo y Ricardo Portocarrero Grados (comps.). Lima: Fondo Editorial del Congreso del Perú.

MARTÍNEZ, José Luis.

2004 Alfonso Reyes/Pedro Henríquez Ureña, Correspondencia 1907OLGUÍN, Manuel. 1914. [1986]. Ciudad de México: F. C. E.

1959 Alfonso Reyes, ensayista. Vida y pensamiento. Ciudad de México: Ediciones de Andrea.

OSORIO, Nelson.

1988 "Mariátegui y Amauta en el contexto de los años veinte", Nuevo Texto Crítico. Año 1, nº 2 (II Semestre 1988): 315-327.

REYES, Alfonso.

1997 "Pasado Inmediato", en Obras completas Tomo XII. Ciudad de México: F. C. E. 
VERA CUSPINERA, Margarita.

1981 "Los ateneístas, críticos de su tiempo", en VV.AA. Alfonso Reyes. Homenaje de la Facultad de Filosofía y Letras. Ciudad de México: UNAM. 